\title{
Making it Real or Sustaining a Fantasy? Personal Budgets for Older People
}

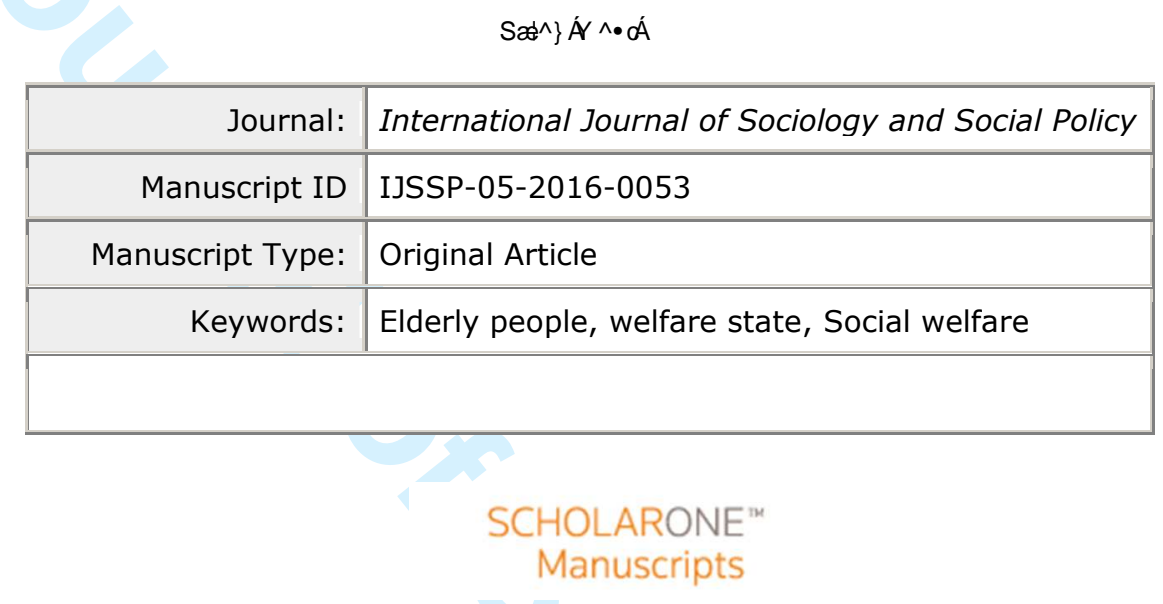




\section{Making it Real or Sustaining a Fantasy? Personal Budgets for Older People}

The restructuring of English social care services in the last three decades, as services are provided through a shifting collage of state, for-profit and non-profit organisations, exemplifies many of the themes of governance (Bevir, 2013). As well as institutional changes, there have been a new set of elite narratives about citizen behaviours and contributions, undergirded by modernist social science insights into the wellbeing benefits of 'self-management' (Mol, 2008). In this article, we particularly focus on the ways in which a narrative of personalisation has been deployed in older people's social care services. Personalisation is based on an espoused aspiration of empowerment and autonomy through universal implementation to all users of social care (encapsulated in the Making it Real campaign [Think Local, Act Personal (TLAP), no date)], which leaves unproblematised the ever increasing residualisation of older adult social care and the abjection of the frail (Higgs and Gilleard, 2015). In this narrative of universal personalisation, older people are paradoxically positioned as 'the unexceptional exception'; 'unexceptional' in the sense that, as the majority user group, they are rhetorically included in this promised transformation of adult social care; but 'the exception' in the sense that frail older adults are persistently placed beyond its reach. It is this paradoxical positioning of older adult social care users as the unexceptional exception and its ideological function that we seek to explain in this article.

In constructing an explanation of this paradox, we follow a strand of de-centred and postfoundationalist thought (Bevir,2013), which draws on post-structuralist discourse theory (Laclau and Mouffe, 1985) and (Lacanian) psychoanalytic theory (Glynos and Howarth, 2007), in what has been variously described as 'the post-structuralist appropriation' of Lacan (Stavrkakis, 2007) and 'third generation post-structuralism' (Howarth, 2013). Central to this critical explanatory complex is the post-Marxist theory of hegemony (Laclau and Mouffe, 1985; Howarth, 2009), understood as both a form of rule and a kind of political practice (Howarth, 2009). On this reading, narratives (or discourses) are constitutive of identity and action. Particular and disparate sets of demands are linked together, according to a logic of equivalence into a totality or universal (Howarth, 2013), thereby making contingent subject positions available.

The ethical, ideological, political and normative dimensions of narratives operate at different levels of subjectivity, requiring critical analysts to examine both more or less conscious political/rhetorical tactics and the ways in which the fantasmatic dimensions of narratives act on unconscious desires. In this article, we focus on the latter because it has largely been ignored in academic discussions of personalisation, which tend to remain at the level of normative and policy analysis, thereby overlooking its ideological and ethical dimensions (see Author 1, 2013). In so doing, we draw additionally on recent theorising in critical social gerontology, which posits, on the one hand, a generalised tendency in policy to downplay the distinctiveness of ageing in favour of an expanded and ageless middle age or 'third age' (Laslett, 1991), and, on the other hand, a growing marginalisation and feared social imaginary of advanced old age, the so-called 'fourth age imaginary' (Higgs and Gilleard, 2015). We argue that this complex ageist assemblage (age blindness combined with the marginalisation of 'deep', 'frail' old age [ibid, p 19]) is so culturally pervasive that it has enabled the positioning of the majority of older adult social care users as the unexceptional 
exception' to remain unproblematised, thereby ideologically screening out the impossibility of its universal application.

The article proceeds as follows: the first section sets out our account of personalisation as a universalising approach. We explore its contribution as an empty signifier,contrasting the universalism of its claims with the relatively low take up of personal budgets by older people. Then we draw on interview data from a project with a large national charity which sought to increase older people's take up of personal budgets in order to illustrate the persistence of policy-makers in seeking to address their lack of take-up to date, and to highlight the explanations that are typically invoked in response to that failure. The third section draws on critical social gerontology's recent theorisation of ageism and the ways in which older adult social care has both played a central role in the development of this new ageism and is the arena in which it continues to be played out. Finally, we conclude by arguing for greater attention to be paid to the ideology and ethics of personalisation among both policy makers and advocates.

\section{Making it Real: universalising personalisation}

Scholars of hegemony are centrally concerned with the metonymical sliding of the meaning of signifiers as they comes to be contingently articulated with others in logics of equivalence (Howarth, 2013). We have discussed, elsewhere, the ways in which personalisation has been articulated with, and indeed, has come to stand for, a more generalised transformation programme of adult social care (Author 1, 2013), a revolution in public services in general (Author 2, 2011) and a return to a more wholesome vision of welfare in which the old wrongs of exclusionary citizenship are put right in a Beveridge settlement for the $21^{\text {st }}$ century (Author 1, 2013; Glasby et al, 2011). We refer readers to these earlier discussions, but the point we want to make here is that as stand-in for this broader, transformative governance project, personalisation must have universal appeal.

In pursuit of this universalising appeal, personalisation has come to condense a set of contingent demands: for control over how disabled people live their lives; for less paternalistic and more person-centred welfare; for the right to be an equal and active citizen; but also for the need to find ways of 'doing more with less' by positioning social care users as rational economisers of their own resources (See Author 2, 2011 for a fuller discussion of the many meanings of personalisation). Like other empty signifiers, personalisation is, then, 'the symbolic representation of a flawed and ultimately elusive universality', serving the function of standing in for a fullness that is lacking (Howarth, 2013, p 82). Without this universalist promise, personalisation would merely be a targeted programme for particular groups of social care users, rather than a programme that promises the transformation of adult social care, and, indeed, public services (Author 2, 2011) and welfare in general (Glasby et al, 2011).

From this theoretical perspective there is nothing unique to personalisation in fulfilling this role as empty signifier; the world is replete with such empty signifiers and social and political life depends on this kind of hegemonic manoeuvring. However, what third generation post-structuralist discourse theorists draw particular critical attention to is the way in which discourses come to 'grip' subjects and to hold hegemonic complexes in place even when, in moments of dislocation (or governance 'dilemmas', in Bevir's (2013) terms) their incompleteness is revealed (see in particular, Glynos and 
Howarth, 2007, but also Fotaki, 2010). What these critical scholars have drawn attention to is the fantasmatic dimension of narratives (Glynos and Howarth, 2007); narrative forms which act to 'suture' (Laclau and Mouffe, 1985) the radical gap (Zizek, 2012) between what we call 'the Real of personalisation' (an idea which captures the impossibility of extending personalisation to all user groups in the current circumstances of adult social care) and 'idealised universal personalisation'.

Typical of such fantasmatic narratives is the way in which they contain both a promise and an explanation for the failure to achieve that promise, thereby, maintaining desire in it. Evidence of failure, particularly in relation to older people's take up of personal budgets and direct payments is readily available.

As part of the broader personalisation agenda within English social care service, personal budgets are now offered to all older and disabled people as the mechanism through which they manage their care spending allocation (HM Government, 2007). Budgets can be held by the individual as a direct payment, by the local authority as a managed personal budget or a third party as an individual service fund. However government policy documents have been emphatic that the best way to manage the funds is as a direct payment to citizens, given that this should give maximum choice and control to the person with an eligible need (Routledge and Carr, 2013). Take up for younger people with disabilities has grown substantially, whilst uptake amongst older people has remained at a lower level, particularly for direct payments (Age UK, 2013; Lymbery, 2010; Netten et al, 2012; Author 1, 2013; Lloyd, 2014). Around 10 per cent of older people receive their social care spend as a direct payment, compared to 24 per cent of younger people with disabilities (HSCIC, 2014).

Reflecting on low levels of uptake in an earlier phase, the National Personal Budget survey in 2011 reported: 'older adults are less likely to use direct payments, less likely to know how their personal budget was managed, and more likely to have a personal budget managed by the council - all these factors are associated with less positive outcomes' (Hatton and Walters, 2011, p.26). Concerns have therefore been raised about the extent to which older people are being left behind by a personalisation agenda which has concentrated benefits more on younger disabled adults and people using mental health services (Glendinning et al, 2008; Wilberforce et al, 2011; ADASS, 2012; Routledge and Carr, 2013; Woolham and Benton, 2013; Lloyd, 2014). An Age UK report on personal budgets stated: 'personal budgets are failing to deliver the benefits to older people which younger disabled people are able to achieve' $(2013$, p9). Some people who ostensibly had a personal budget did not even know that they had one (Age UK, 2013, p.11). The Age UK report goes on,

Clearly, a switch to personal budgets needs to be much more than an administrative or book-keeping exercise: it needs to fundamentally change the experience of service users. No local authority could be considered to be performing well unless this transformation in the experience of receiving care and support is achieved. And, as older people are the largest group of social care users, personalisation cannot be working well unless it's working for older people. (Age UK, 2013, p.11)

Here, then, there is an explicit acknowledgement that personalisation cannot be deemed to have been a success (as a transformative project) until older people, as the majority user group, see a meaningful transformation in their experience of care and support. 
Government policy makers have acknowledged the lack of progress made in relation to older people's take up of personal budgets, and have suggested a number of routes to tackle them, for example through enhancing older people's access to independent sources of information, advice and advocacy (ADASS, 2012; Age UK, 2013; Routledge and Carr, 2013; TLAP, 2015). As a document published by Think Local, Act Personal on increasing older people's take up of personal budgets put it:

This is a major cultural change for the people commissioning and delivering social care and for those using it - in particular older people for whom individualised funding is very new. This places a premium on effective change management strategies, especially for those starting from a lower base. For most councils it will take some time to achieve these shifts (Routledge and Carr, 2013, p4).

Recognition of the need to sustain momentum around personalisation appeared to be the prompt for the Making it Real framework, launched by TLAP in 2012. The launch document expressed its intention as being to help organisations check their progress and decide what they need to do to keep moving forward to deliver real change and positive outcomes with people' (TLAP, 2012, p2). The ambition of the approach was to offer practical steps to help move personalisation closer to its universalising promise:

Using Making it Real means that councils, organisations and all partners can look at their current practice, identify areas for change and develop plans for action. It can be used by any organisation involved in providing care and support including councils, providers of home based support and those providing residential and nursing care $(2012$, p.3).

The language of Making it Real, and the commitment to local activity and action plans to achieve that, highlights the assumption within government policy that more personalised care services can be best achieved through a more intense application of the existing personalisation policies.

In order to interrogate the adequacy of the government's response to older people's low take up of personal budgets, we draw below on original data from an evaluation of a national ageing charity's project to increase take-up of personal budgets, which was commissioned by the charity and undertaken by one of the authors (Author 2). 


\section{Explaining the lack of progress on personal budgets for older people}

The project was located in five local sites, with local branches of the charity aiming to work in partnership with their local authorities to increase older people's awareness of and take up of personal budgets (for more details see Ellis Paine et al, 2015). The evaluation involved a range of elements, including a scoping study, a series of participatory workshops with programme staff, the collection and analysis of monitoring and outcomes data, interviews with programme coordinators and managers, focus groups and interviews with volunteers, and interviews and observations with older people. For this article we draw only on data from a series of semi-structured, in-depth interviews with local third sector workers charged with delivering the project on the ground.

All interviews were audio-recorded and transcribed verbatim. The transcripts were thematically coded and analysed using QSR's Nvivo 10 a qualitative analysis software package. An initial coding frame was created based on broad categories and themes that included, for example, 'background and context'; 'local partners'; 'volunteers'; 'Local Authority relationships' and 'Outcomes'. Subsequent analyses of these themes led to the creation of more finely grained sub-codes. The interview extracts selected for use in this article are exemplars which illustrate the three explanations which interviewees gave for older people's relatively low take-up of personal care budgets. We supplement the interview extracts with secondary data which further supports each of the three explanations:

\section{Local practices of resistance to national policy directives}

One explanation that emerged from the evaluation project is that workers in the third sector ageing charity felt local authorities were not informing people about the option to have a personal budget or direct payment. An interviewee from one of the local charity branches said:

What we're finding is when [our worker] goes out to see people they haven't been explained to about a personal budget. They've maybe been told [by a social worker], "Oh well there is a personal budget," and then on to something else, so people aren't picking up on that.

Another third sector interviewee, in a different locality, said:

People were still on paper being put on personal budgets but were still receiving the managed prescribed care services, domiciliary care services...I think [the council] saw a difference between personal budgets and direct payments and encouraged people to stay on managed personal budget. But under the ideology of personalisation they should be one and the same, whether it's managed by the local authority or not.

This explanation foregrounds the role of social workers and local authority managers in resisting the drive for personal budgets and discouraging older people from taking them up (Ellis, 2007, 2014). Such resistance can itself be explained in a number of ways. It may be a reaction against the perceived neo-liberalising potential of personal budgets (Ferguson, 2008). It could be a response to the funding cuts which are placing intense gatekeeping pressures on staff (discussed 
further below). Alternatively, it can be, as many disability campaigners have argued and as government policy documents have often implied, an indication of a social care culture which remains rooted in 'institutionalisation, control, paternalism and inflexibility in services and reliance on a "deficit" model rather than on the philosophy of independent living' (Beresford, 2014, p. 167). It is this explanation which is most consistent with the Making it Real strategy of increasing the pressure on councils to make personalisation 'real' at a local level.

\section{Lack of money in local authority social care budgets.}

A second explanation of the lack of progress in personal budgets for older people relates to the very intense cuts to social care spending in the current climate of fiscal austerity. Whilst social care budgets have been under pressure for many years, the very high levels of recent cuts to local government budgets have made this issue particularly pronounced. The Local Government Association (LGA) estimates an annual care funding shortfall of f700million (LGA, 2015). Interviewees for the evaluation talked about how their local authorities were struggling to reconcile policies around personalisation with the need to massively reduce spending. As one voluntary sector interviewee put it, reflecting on local authority disengagement with the personal budget project in her area:

[P]ersonalisation has not fitted in terms of the cost of personalisation with the council budget cuts and what we've seen is an out and out reluctance... to support and engage proactively and be part of the project coupled with a real resistance to realising... personalisation in [this locality].

The issue of underfunding of older people's care services has been highlighted by a number of authors. With many older people only receiving enough state support to pay for short home visits to help with essential tasks such as getting washed, dressed and preparing food, it is not clear that there is scope to use this budget in a more person-centred way (Age UK, 2013; Author 2, 2014). Social care in England persists in a state of perpetual and worsening crisis (Age UK, 2014). While the population of the over 65s increased by $13 \%$ between 2005 and 2012, the percentage of the over 65 s receiving support for social care dropped by $35 \%$ with no diminution of care need (Age UK, 2014). Care funding for the over 65s is now almost universally limited to those with substantial and critical needs only, according to the national Fair Access to Care criteria, which means that those seeking support are already effectively in crisis. As Lloyd puts it (2014, p61): 'Reductions in the level of resources within personal budgets are to be expected, despite evidence that unless the level of the budget is set higher than that needed for basic help there will be no increase in the flexibility for individuals in organising support.' Age UK has pointed out that this stands in contrast to services for younger disabled people, for whom "personal budgets can be relatively large and there is a real focus on "living life" when planning support, whereas personal budgets for older people are often considered to be purely about personal care and maintenance and, as a result, tend to be much smaller' (Age UK, 2013, p71). Older people in residential accommodation are seen as particularly likely to miss out on the self-actualising promises of personalisation (Carr, 2009). 
One response to this issue has been to campaign for more money to come into the social care sector. Beresford concludes from a recent large project on care services 'It was difficult to see from the project how meaningful personalisation could be rolled out and achieved for all on a sustainable basis for the future, without social care being securely and adequately funded' (2014, p.167). However, proposals to bring more money into care services through an insurance approach or to take money from people's estates after death, have proved too controversial to gain traction, and even the relatively limited proposal to introduce a cap on individual care spending for self-funders has been delayed until 2020 (Triggle, 2015). In the absence of government willingness to acknowledge and address the underfunding of care, it is the first explanation (cultural resistance to personal budgets for older people within local authorities) that is privileged.

\section{Lack of fit between personalisation and old age}

There is also a third explanation, which focuses on the poor fit between the rhetoric of personalisation and the reality of social care services for older people. In this explanation, older people are recognised to have limited interest in taking up a personal budget or direct payment because of anxiety about the stress of doing so at a time of crisis and growing frailty (Glendinning et al., 2008; Moran et al., 2012). One third sector work interviewed for the evaluation project said:

I think one of the other difficulties is the criteria for being eligible for social care in [this local authority] has been squeezed and squeezed and squeezed to the point where... what older people are being assessed as eligible for is now so tight that you are actually quite limited in how creative you can be and how much choice you can have, because we are talking about very, very, very top-end dependent people at end of life.

Another said,

for social services [personal budgets] is such a small speck on their radar. And actually personal budgets are such a small speck on their radar, because they're very much dealing with more of the crisis situations, so this all seems very nice and pink and soft and fluffy

These quotes highlight the disjuncture between the promise of personal budgets and the reality of social care as a cash-starved service encountering people in crisis and at end of life. An Age UK report similarly highlighted the frailty of older people in the social care system

'One Age UK service reported that just over one quarter of the 100 people referred over a six month period died before receiving a personal budget. All of them were awaiting allocation to a social worker, waiting for an assessment or moving from intermediate care which illustrates just how frail and ill people referred for an assessment are' (Age UK, 2013, p.75) 
We have suggested then that there are three types of explanation of the failure to include the older majority in the personalisation agenda. To recap, these are: 1) that social workers and managers have not sufficiently encouraged older people to take up personal budgets; 2) that the funding conditions facing local authorities are not conducive to the inclusion of the older majority; and 3) that the ideals of personalisation (qua choice and control) ill fit the realities of frail older people (again the majority of social care users). The second and third of these explanations point to rather fundamental conditions of (im)possibility for the successful application of personalisation to the majority older age group. Even the first explanation contains some element of the second and third in so far as frontline staff may to a greater or lesser extent, be compelled to develop practices which mask the patent absence of the right conditions, the most fundamental of which is that older people consistently receive lower levels of funding than other user groups (Moran et al, 2012).

In this interpretation, the relationship between the elite narrative and frontline practice is not one in which frontline workers are the saboteurs of a progressive agenda for older people. Rather it is at the frontline that staff have to develop meaningful practices which seek to mask or deflect from the reality of low demand. The third sector workers involved in the evaluation project had to be creative in the face of limited scope to increase older people's take-up of personal budgets. In one site, for example, the project workers expanded the definition of personal budgets so that it better fitted the sorts of people that they could support, e.g. early intervention work with people who were not yet eligible for personal budgets, or who were self-funding their care.

Yet, in discussions about personalisation among its advocates and promoters, there is a tendency to draw on an idealised personalisation, which currently works only for a minority, to scapegoat professionals for their failing to make it a reality, and to disavow what we might term 'really existing personalisation', which fails to work and, given current conditions, cannot work, for most older people in the care system. This, we argue, merits some reflection because in so doing, we may gain a different vantage point from which to see a way out of the current impasse, in which national policy-makers swing between encouraging and impugning local authorities/social workers as a way to drive progress, and local authorities and social workers express frustration at the ways that the national financial context thwarts the potential of personalisation to improve the lives of vulnerable people (LGA, 2015; Hart, 2014). We want to argue that far greater attention needs to be paid to the ideological dimension of personalisation than hitherto.

\section{The role of the new ageism in sustaining the fantasy of universal personalisation}

In claims about the universalisation of personalisation to older service users, it is never entirely clear who the older service users are. Both among advocates and neutral observers of the process of universalization, discussions are of a rather nebulous category of 'older person' or 'older people' . Yet, in social gerontology and the sociology of ageing, there has long been recognition that there has been considerable fragmentation of ageing, old age and later life. The notion of a 'third age' has been very prominent in the ageing literature for over two decades, being first coined by Laslett in 1989. Associated with the post-war baby boom generation, the third age, as a 'cultural field' (Gilleard and Higgs, 2013), has brought with it the possibility for many to eschew age as the primary marker of identity in later life and has resulted in a kind of permanent extension (for some) of midlife, or ageless ageing. New consumer lifestyle practices such as exercise and diet along with 
products such as cosmetics, aspirational medicine, prosthetics and mobility aids bring new possibilities for self-fulfilment and realisation to this phase of life, that simply were not available before (Ibid). What should be particularly noted here is that being able bodied is not a condition of entry to this cultural field. People with disabilities that pre-date retirement, in theory, can celebrate their disabled identity free form the taint of agedness, just as gay retirees can celebrate their gay identities. Although disability activism and age activism have historically had a difficult relationship (Gilleard and Higgs, 2010), to the extent that the cultural field of the third age is an ageless one, personalisation and its discourse of autonomy, self-direction, self-actualisation, choice and consumption fits it well.

These universalist aspirations arguably make a claim to timelessness, although they can be temporally and geographically located within a particular set of governing rationalities in a distinctive phase of English governance (Bevir, 2013). Challenges in the 1980s to the legitimacy of the bureaucratic state from new social movements (particularly in relation to disability campaigners) and new sources of accountability (such as the Human Rights Act in the 1990s), arguably contributed to a political context in which people with disabilities had to be admitted to full citizenship (Rummery, 2006). As disability campaigns for independent living and person-centred support came to be accommodated by the state, the ethical basis for excluding older people came under challenge. The structural intertwining of older people's support and support for younger people with disabilities within local authority social services departments further weakened the basis for claiming that older people represented a special case. The Putting People First Concordat, signed between government and key stakeholder organisations in the social care sector (HM Government, 2007) which broadened direct payments into personal budgets, affirmed a common approach for all age groups and disabilities.

From a rights standpoint, an undifferentiated and ageless policy of personalisation appears plausible and, even, appealing. Personalisation is a narrative of perfection and perfectibility (Author 1, 2013), a mode of conceptualising and talking about the personhood and citizenship of those who have hitherto been denied full recognition as persons and full entitlements to citizenship, a status which those of the third age with independent means can now claim. With its universal implementation, it is asserted the older, old majority can, with certain modifications, also be comfortably inserted into this scenario of perfection.

For the younger disabled, although far from fully realised, personalisation's autonomising potential is not wholly unachievable and, indeed, evidence shows that 'really existing personalisation' can bring substantial benefits (see e.g. Waters and Hatton, 2014). However, as we have already noted, personalisation's empowering potential appears to be much more elusive for older adult social care users. For this group of older adults, it is more appropriate to talk of 'the fourth age' (Grenier, 2007; Higgs and Gilleard, 2015)

The idea of a fourth age is not unproblematic. Scholars agree that current cultural and political discourse privileges the younger old of the third age, but marginalises those in 'real old age' (Higgs and Gilleard, 2014 (See also Grenier and Phillipson, 2013; and Lloyd et al, 2013; Author 1, 2014). For some, though, the designation of a fourth age is too suggestive of finality, and neglects the ways in which the older old can express and achieve agency even in conditions of frailty (see, for example, Grenier and Phillipson, 2013 and Lloyd et al, 2013). For our purposes, however, there is something 
very useful in Higgs and Gilleard's (2015) theorisation of the fourth age as 'a social imaginary' (see also Gilleard and Higgs, 2010) which is culturally produced, but also practically shapes the conditions of the frail elderly. Of particular interest in their analysis is the way in which a neglectful social care system is said to have led to the marginalisation of the frail elderly, leaving them in 'a condition of high but poorly specified risk' (Higgs and Gilleard, 2015, p. 67), and placing them outside of the current policy discourses of self-management, co-production' (ibid, p 67) and, for that matter, personalisation. They argue that the social imaginary of the fourth age has arisen in practices of care rationing, in which a key condition of eligibility for state support is a diagnosis of irreversible frailty. There has been increased policy emphasis on community care over the last three or four decades - . supporting people to live in their own homes has become the key policy driver -, but, without sufficient funding to assure good quality care in this setting (Author 1, 2014), residential care has become a last resort for those unable to manage. For Higgs and Gilleard, this has lead to a 'steady "compression of morbidity" within the institutions of old age care' (Higgs and Gilleard, 2015, p. 90). In this way, then, care for older people in the community ('ageing in place') is an underfunded policy aspiration, while residential care for the frail and 'frailed' (Higgs and Gilleard, 2015; Grenier, 2012) has become a terminal destination for those who have failed to age agelessly.

In Higgs and Gilleard's reading, the fourth age is both the counterpart to the third age, a residual category of old age that cannot be folded into the positive, consumer-driven discourse of the third age (Author 1, 2014), and a feared and dreaded social imaginary. This further compounds the abjection of the frail and their low paid care workers 'struggling in an unending battle against the threat of unmanageable abjection' (Higgs and Gilleard, 2015, pp 90-91). The frail have few possibilities for resistance and the assertion of personhood, but are, instead, the subjects of 'intractable abjection' (Higgs and Gilleard, 2014). As they so succinctly put it: 'The frailed individual is caught in a system of care that is doled out, rationed and increasingly driven by a rhetoric of choice within a social reality made up of constraint and dependency' (Higgs and Gilleard, 2015, p77).

From the position of the older old majority, then, the gap between an idealised narrative of transformation, autonomisation, personhood and empowerment and the situation of frail older people, approaching care services for the first time at a moment of crisis, seems unbridgeable. The insistence on 'Making it Real' is a fantasy that places out of sight this radical gap between the conditions of crisis and abjection afflicting the older old majority of people in need of care and the ideal of universal transformation through personalisation. Its idealised gesture of inclusion within a transformed care system that promises autonomy, full citizenship and personhood for all, disavows the way in which an indifferent, and arguably brutal, social care system itself creates the conditions by which older social care users are discounted from its logic from the very start. This, we suggest is not merely a practical matter of universalisation through change management processes - 'Making it Real'. Rather, what is at stake is a more ontological question about the contemporary sociocultural and political-economic circumstances of ageing. This 'new ageism' in which there is a denial of older age as a distinctive phase of life (Bigg et al, 2006; Andrews, 1999; Grenier, 2012) serves to fuel the fear, marginalisation and 'intractable abjection of the frail' (Higgs and Gilleard, 2015), creates the conditions in which the paradoxical position of the majority of social care users as 'the unexceptional exception' raises few eyebrows among the policy elite. 


\section{Conclusion}

We have sought here to explain the paradoxical positioning of older social care users as 'the unexceptional exception' in the narrative of universal personalisation. We have done so by drawing on a species of de-centred and post-foundationalist interpretation, which enables the interrogation of the ideological, ethical dimension of hegemonic narratives and the role of fantasy in sustaining them even in the face of chronic policy and governance dilemmas. We have argued that personalisation, as a master signifier of the transformation of public services and welfare, requires full inclusion and universal implementation. However, while personalisation is deemed to be a success for the minority of younger users, older people, as the majority, have not reaped its benefits. Yet this has not resulted in any serious assertion by elite policy makers of the differences between older and younger social care users; rather what has emerged is a change management approach Making it Real -which promises to achieve full inclusion and, thereby, to maintain desire/belief in it. In making our argument that universal personalisation is a fantasy, we have drawn, in particular, on the work of Higgs and Gilleard and their concept of the fourth age imaginary. Universal personalisation, we have argued, may be appropriate to a third age minority (who may be eligible for social care services because of long-term disability), but sutures the impossibility of its application to those experiencing frailty in the fourth age, currently the majority of those eligible for personal budgets.

Our conclusion is not that person-centred policies have no place in policies for older people, or that elder care services do not need to be improved. Rather we are explaining the disjuncture between the elite narrative that older people's care and support will be improved by entitlements to a personal budget, and local practices that seem to consistently fail to realise this ambition. We argue that this disjuncture is not amenable to a policy fix. There is much that is laudable in the gesture of inclusion of the older old majority within personalisation's big tent. It would clearly be churlish to claim that the humanity of the older old is not in desperate need of reclaiming (Baars and Phillipson, 2013). But, if that idealised gesture of universalisation blinds us to the really existing conditions of its realisation, we see a real danger in it inadvertently becoming an ageist ideology. In the final analysis, we suggest that this is not a matter of 'Making it Real', but one of tarrying with the Real of older age.

\section{References}

Age UK (2013), Making Managed Personal Budgets work for older people, London: Age UK, http://www.ageuk.org.uk/professional-resources-home/services-and-practice/care-andsupport/personalisation-hub/making-personal-budgets-work-for-older-people/ [accessed 23.1.2014]

Age UK (2014), Care in Crisis 2014. http://www.ageuk.org.uk/Documents/ENGB/Campaigns/CIC/PDF\%20Care\%20in\%20Crisis\%20\%20What\%20next\%20for\%20social\%20care\%202014.pdf?dtrk=true [accessed 27.10.15] 
ADASS (Association of Directors of Adult Social Services) (2012), The Case for Tomorrow, London: ADASS.

Andrews, M. (1999), 'The seductiveness of agelessness'. Ageing and Society, 19/3: 301-318.

Baars, J. and Phillipson, C. (2013), 'Connecting meaning with social structure: theoretical foundations' in Baars, J., Dohmen, J., Grenier, A. and Phillipson, C. Ageing, Meaning and Social Structure. Connecting Critical and Humanistic Gerontology. Bristol: Policy Press.

Biggs, S., Phillipson, C., Money, A. and Leach, R. (2006), 'The age-shift: Observations on social policy, ageism and the dynamics of the adult lifecourse'. Journal of Social Work Practice, 20/3: 239-250.

Kate Baxter , Parvaneh Rabiee \& Caroline Glendinning (2013), Managed personal budgets for older people: what are English local authorities doing to facilitate personalized and flexible care?, Public Money \& Management,33:6, 399-406, DOI: 10.1080/09540962.2013.835998

Beresford, P. (2008), 'Whose personalisation?' Soundings, 40, Winter, pp 8-17.

Bevir, M. (2013), A Theory of Governance, Berkeley, Ca: University of California Press.

Carr, S. (2009), At a glance 17: Personalisation briefing: Implications for residential care homes, London: Social Care Institute for Excellence.

Coole, D. (2012), 'Reconstructing the elderly. A critical analysis of pensions and population policies in an era of demographic ageing'. Contemporary Political Theory 11, 1: 41-67.

Equality and Human Rights Commission (EHRC) (2011), Close to Home: An inquiry into older people and human rights in home care, London: EHRC, http://www.equalityhumanrights.com/publication/close-home-inquiry-older-people-and-humanrights-home-care.

Ellis, K. (2007), Direct payments and social work practice: the significance of 'street-level bureaucracy' in determining eligibility, British Journal of Social Work, 37, 3: 405-22.

Ellis, K. (2014), Professional discretion and adult social work: exploring its nature and scope on the front line of personalisation. British Journal of Social Work, 44(8), 2272-2289.

Ellis, K. (2015), Personalisation, ambiguity and conflict: Matland's model of policy implementation and the 'transformation' of adult social care in England. Policy \& Politics, 43(2), 239-254.

Evans, T. (2013), Organisational rules and discretion in adult social work, British Journal of Social Work, 43, 4, 739-58.

Ferguson, I. (2007), 'Increasing User Choice or Privatizing Risk: the Antimonies of Personalization', British Journal of Social Work, vol 37, pp 387-403. 
Fotaki, M. (2010), 'Why do policies fail so often? Exploring health policy-making as an imaginary and symbolic construction.' Organization, 17/6: 703-720.

Gilleard, C. and Higgs, P. (2010), Ageing without Agency: Theorizing the Fourth Age. Aging and Mental Health, 14, 2,121-128.

Gilleard, C. and Higgs, P. (2013), Ageing, Corporeality and Embodiment. Aththem Press, London, New York and Delhi.

Glasby, J. and Littlechild, R. (2009), Direct payments and personal budgets: putting personalisation into practice, Bristol: Policy Press.

Glendinning, C., Challis, D., Fernandez, J.-L.Jacobs, S., Jones, K., Knapp, M., Manthorpe, J., Moran, N., Netten, A., Stevens, M. and Wilberforce, M. (2008), Evaluation of the Individual Budgets Pilot Programme: Final Report (Social Policy Research Unit, University of York, York).

Glynos, J. and Howarth, D. (2007), Logics of Critical Explanation in Social and Political Theory. Routledge, London and New York.

Glynos, J. (2008), 'Self transgressive enjoyment as a freedom fetter', Political Studies 56, pp. 679704.

Grenier, A. 2012. Transitions and the Lifecourse. Challenging the Constructions of 'Growing Old'. Policy Press, Bristol.

Grenier, A. and Phillipson, C. (2013), 'Rethinking agency in later life: structural and interpretive approaches', in Baars, J., Dohmen, J., Grenier, A. and Phillipson, C. Ageing, Meaning and Social Structure. Connecting Critical and Humanistic Gerontology. Bristol: Policy Press.

Hatton, C. and Waters, J. (2011), National Personal Budgets Survey 2011. London: Think Local, Act Personal, In Control, University of Lancaster.

HM Government, (2007), Putting people first: A shared vision and commitment to the transformation of adult social care. London: HM Government.

HSCIC (Health and Social Care Information Centre) Community Care Statistics, Social Services Activity, England, 2013-2014, (2014) Final Release. http://www.hscic.gov.uk/catalogue/PUB16133/commcare-stat-act-eng-2013-14-fin-rep.pdf (accessed 24 April 2016).

Higgs, P. and Gilleard, C. (2015), Rethinking Old Age. Theorizing the Fourth Age. Palgrave Macmillan, London.

Howarth, D. (2013), Poststructuralism and After. Structure, Subjectivity and Power. Palgrave Macmillan.

Laslett, P. (1991), A Fresh Map of Life. The Emergence of the Third Age. Cambridge Massachusettes: Harvard University Press.

Lloyd, L., Calnan, M., Cameron, A., Seymour, J. and Smith, R. (2013), Identity in the fourth age: Perseverance, adaptation and maintaining dignity. Ageing and Society, DOI: 
$10.1017 / \mathrm{S} 0144686 \times 12000761$.

LGA (Local Government Association) (2015), Spending Smarter: A Shared Commitment, London: LGA.

Lymberry, M. (2010), A new vision for adult social care? Continuities and change in the care of older people. Critical Social Policy, 30, 5, 5-26.

Macnicol, J. (2015), Neoliberalising Old Age. Cambridge University Press.

Mol, A. (2008), The Logic of Care, London, Routledge

Moran, N., Glendinning, C., Wilberforce, M. Stevens, M., Netten, A., Manthorpe, J., Knapp,

M. Fernandez, J.-L., Challis, D. and Jacobs, S. (2012), Older people's experiences of cash-for care schemes; evidence from the English individual budget pilot projects. Ageing and Society, 33, 5, pp. 826-851.

Netten, A., Jones, K., Knapp, M., Fernandez, J.-L., Challis, D., Glendinning, C., Jacobs, S., Manthorpe, J., Moran, N., Stevens, M. and Wilberforce, M. (2012), 'Personalisation through Individual Budgets: does it work and for whom?' British Journal of Social Work, 42 (8): 1556-1573.

Routledge, M and Carr, S. (2013), Improving personal budgets for older people: A review, TLAP and SCIE, London.

Rummery, K. (2006), 'Disabled citizens and social exclusion: the role of direct payments', Policy and Politics, vol 34, no 4, pp 633-650.

Stavrakakis, Y. (2007), The Lacanian Left: Psychoanalysis, Theory, Politics. Edinburgh University Press, Edinburgh.

Think Local, Act Personal (no date), Making it Real: marking progress towards personalised, community-based support, http://www.thinklocalactpersonal.org.uk/ library/Resources/Personalisation/TLAP/MakingltReal.pd $\underline{f}$

Think Local Act Personal (TLAP) (2015), Getting better outcomes: Personal budgets and older people: Follow up report, March 2015, TLAP, London.

Tonkiss, K. and Bloom, T. (2016), Rethinking Non-Citizenship. Discover Society Issue 31 (http://discoversociety.org/2016/04/05/focus-re-thinking-noncitizenship/.

Triggle, N. (2015), 'Care costs cap delayed until 2020, BBC News, http://www.bbc.co.uk/news/health-33552279

Waters, J. and Hatton, C. (2014), Third National Personal Budgets Survey, London: In Control/Lancaster University/TLAP, http://www.incontrol.org.uk/media/168205/third\%20national\%20personal\%20budget\%20survey\%20oct2014.pdf 
Wilberforce, M., Glendinning, C., Challis, D., Fernandez, J-L, Jacobs, S., Jones, K., Knapp, M., Manthorpe,J., Moran, N., Netten, A., Stevens, M. (2011), 'Implementing consumer choice in longterm care: The impact of Individual Budgets on social care providers in England,' Social Policy and Administration, 45,5, pp. 593-612.

Woolham, J. and Benton, C. (2013), The costs and benefits of personal budgets for older people: evidence from a single local authority. British Journal of Social Work, 43(8), 1472-1491.

Žižek, S. (2008), The Ticklish Subject. Verso, London and New York.

Žižek, S. (2012) Less than Nothing. Hegel and the Shadow of Dialectical Materialism, Verso. 